\title{
Classification of lipoproteins and lipoprotein disorders
}

\author{
BARRY LEWIS \\ From the Department of Chemical Pathology and Lipid Disorders Clinic, Royal Postgraduate Medical School, \\ Hammersmith Hospital, London
}

In the past 10 years it has become clear that hyperlipidaemia is a major risk factor for ischaemic heart disease. It is by no means the only one, and has to share responsibility with hypertension, smoking, diabetes, and with lesser risks such as obesity and hyperfibrinogenaemia. Its importance is that with existing knowledge it is an eminently remediable state. We have learned in the past four years that when therapeutic agents which lower serum lipids are administered to unselected, middle-aged men, the incidence of ischaemic heart disease decreases by $25-60 \%$ (Christakis, Rinzler, Archer, Winslow, Jampels, Stephenson, Friedman, Fein, Kraus, and James, 1966; Dayton, Pearce, Goldman, Harnish, Plotkin, Shickman, Winfield, Zager, and Dixon, 1968; Miettinen, Turpeinen, Karvonen, Elosuo, and Paavilainen, 1972). One may speculate, so far without evidence, that the selective provision of the most appropriate dietary or drug treatment to subjects with specific hyperlipidaemic states might provide even greater benefits; this is especially likely to be true if such treatment can be commenced early in life.

At one time our view of the several hyperlipidaemic states was even more limited by methodology than it is at present, as only cholesterol measurement was practicable; but around 1960 reliable chemical methods became available for triglyceride measurement also (Carlson, 1960). This made it possible to distinguish patients with hypercholesterolaemia, hypertriglyceridaemia, or both, and in 1963 Lees and Hatch (1963) were able to subdivide hyperlipidaemias further by electrophoretic separation of plasma lipoproteins. This has made possible the several current classifications of hyperlipidaemic serum samples: for example, the distinguished advances contributed by Fredrickson, Levy, and Lees (1967) and by the Beaumont Committee of the World Health Organization (1970). However plasma lipoprotein patterns are no substitute for an aetiological classification, and the former approach is to be regarded as provisional pending a more fundamental understanding of the causes of the hyperlipidaemias.
Nevertheless, a knowledge of cholesterol and triglyceride concentrations in serum and of the serum lipoprotein pattern is sufficient for the selection of treatment for a large majority of patients with hyperlipidaemia. Before discussing this approach, it is necessary to discuss the lipoproteins of plasma themselves, as a workable classification of lipoproteins is necessary if we are to classify hyperlipidaemic sera by the lipoprotein pattern present.

Most classifications of lipoproteins are operational, depending upon physical properties such as charge, density, or particle size. They all distinguish four classes of lipoprotein: $\alpha$-lipoprotein (high-density lipoprotein, HDL), $\beta$-lipoprotein (low-density lipoprotein, LDL), pre- $\beta$-lipoprotein (very-low-density lipoprotein, VLDL), and chylomicrons. The particlesize approach groups $\alpha$ - and $\beta$-lipoproteins as $\mathbf{S}$ or small particles, pre- $\beta$-lipoproteins as $\mathbf{M}$ or medium particles, and chylomicrons as $\mathrm{L}$ or large particles (Stone, Thorp, Mills, and Dick, 1970). All these classes contain triglyceride, cholesterol and its esters, and phospholipid in different proportions. For present purposes it is mainly necessary to recall that $\beta$-lipoprotein contains cholesterol as its major lipid while pre- $\beta$-lipoprotein and chylomicrons have triglyceride as their chief lipid component. There is evidence that the main source of chylomicron triglyceride is dietary whereas endogenous triglyceride is largely present in pre- $\beta$-lipoprotein. This classification is certainly an approximation as each class is heterogeneous (Alaupovic, 1971). The more efficient the separation method used, the greater is the number of lipoprotein classes. Pre- $\beta$-lipoprotein in particular includes a very wide range of particle sizes (Werner and Jones, 1972).

More recently, our knowledge of the protein components of the lipoproteins (apolipoproteins) has increased abruptly (Alaupovic, Lee, and McConathy, 1972; Albers and Scanu, 1971; Brown, Levy, and Fredrickson, 1969). There are three groups of apolipoproteins, including some eight or more individual peptides. If lipoproteins are defined by their peptide components, then there are from one to 
several lipoproteins in each class isolated by electrophoresis or ultracentrifugation. We are not yet in a position to relate this information to the hyperlipidaemic states, or even to predict whether it will be widely useful, but it is already of importance in the hypolipidaemias.

Another problem in lipoprotein classification arises from the lability of the molecule, which is a consequence of the relatively weak hydrophobic interactions which constitute fthe main intramolecular forces. Diet-induced changes in $\beta$-lipoprotein composition have been described by Spritz and Mishkel (1969). We have found substantial effects of diet on pre- $\beta$-lipoprotein composition (Mancini, Mattock, Rabaya, Chait, and Lewis, 1973). Furthermore, there is strong evidence for the interconvertibility of certain lipoprotein classes: radioiodine-labelled apoprotein injected in the form of pre- $\beta$-lipoprotein reappears in $\beta$-lipoprotein and it has been suggested that this is the main source of the latter (Levy, Bilheimer, and Eisenberg, 1971). Certainly cholesterol is transferred from $\alpha$-lipoprotein to the lower-density classes (Nichols and Smith, 1965). To some extent, it may be conceptually better to envisage a dynamic system of interconverting lipoproteins, rather than a multiplicity of discrete molecular species.

Another area that may need some revision concerns the transport functions of the lipoprotein classes. It is certainly therapeutically important in a hypertriglyceridaemic patient to know whether the excess of circulating lipid is of immediately dietary origin or endogenous. It is true that in health chylomicron triglyceride is largely of dietary origin, though Mancini et al (1973) have shown that chylomicronlike particles containing endogenous fat appear in the plasma of normal subjects fed high carbohydrate diets. Pre- $\beta$-lipoprotein certainly transports endogenous triglyceride, but we have evidence that dietary fat also appears in this lipoprotein and acutely raises its plasma levels; alimentary lipaemia was found regularly to include a rise of pre- $\beta$-lipoprotein as well as of chylomicrons. The contribution 'of the former is proportionately greatest when smaller, physiological quantities of fat are ingested (February, Mattock, Chait, and Lewis, 1972; Lewis, Chait, February, and Mattock (1973) and this is especially true of saturated dietary fat. Both endogenous and dietary fat can therefore occur, in some circumstances, in both chylomicrons and pre- $\beta$-lipoprotein. For this reason caution is necessary when inferring the origin of triglyceride in hyperlipoproteinaemia from the physical properties of the affected lipoprotein class.

Lastly, it is necessary to define hyperlipidaemia. Is an elevated lipoprotein concentration to be identified by a statistic such as the upper $5 \%$ ? There are no strong biological foundations for so doing, and as lipid levels vary widely from one population to another, a purely statistical device such as this implies that a lipid level which is normal in one community will constitute hyperlipidaemia in another. This may be acceptable for some purposes but is probably untenable if it is desired to establish a cut-off point above which the levels of cholesterol or triglyceride become a risk factor for arterial disease. The extent to which the distribution is skewed also adds to the difficulty of a purely statistical approach. Other approaches include comparison of lipid levels in high-risk and low-risk communities (Keys, 1966); if this is done, much lower cut-off points become probable, and a cholesterol concentration exceeding 220 to $240 \mathrm{mg} / 100 \mathrm{ml}$ would arouse concern. Furthermore, a decision has to be made as to whether normal ranges should be adjusted for age. Both cholesterol and triglyceride concentrations increase between the third and seventh decades in this and all industrialized countries, and this has led some authorities to adjust cut-off points for age on the grounds that the increase is physiological. However, the absence of this increase in some ethnic groups observed by Shaper and Jones (1959) and by Antonis and Bersohn (1960) suggests that the phenomenon may merely reflect an increasing prevalence of hyperlipidaemia in older subjects. Our present practice, which is purely arbitrary, is to accept the latter viewpoint and to use \pm two standard deviations for a London population aged 20-29 years to define the range of normal lipid levels. We currently use an upper limit for serum cholesterol concentration of $260 \mathrm{mg} / 100 \mathrm{ml}$ and for serum triglyceride concentration of $160 \mathrm{mg} / 100 \mathrm{ml}$. We employ the Technicon N-24a method for cholesterol, and for triglyceride we extract according to the Technicon N-78 method but use the Cramp and Robertson (1968) fluorimetric method on the AutoAnalyzer.

Classifications of patients with primary hyperlipoproteinaemia are based on plasma lipoprotein and lipid levels. This is, as I have tried to indicate, a somewhat insecure foundation. It therefore seems appropriate to maintain a flexible and undogmatic approach to classification, keeping it as simple as possible. Pending aetiological classifications it is only necessary to distinguish groups for clinical purposes, ie, for treatment and prognosis, and for this purpose probably three categories are sufficient: hyper- $\beta$-lipoproteinaemia, endogenous hypertriglyceridaemias, and exogenous hypertriglyceridaemia.

Certain combinations of these occur frequently. It is certainly possible to distinguish far more 
patterns than these (de Gennes, 1971; Billimoria, Fahmy, Jepson, and MacLayan, 1971)and, hopefully, it may prove possible to allocate specific treatments and prognoses to other types of hyperlipoproteinaemia. Such is not, in my view, the case at present.

It must be emphasized that there is only a limited relationship between serum lipoprotein patterns and the underlying pathogenesis. As Professor Carlson has said, we are classifying the plasma not the patient (Carlson, 1970). It is probable that more than one aetiology may underlie a given lipoprotein pattern. Carter, Slack, and Myant (1971) have suggested that there may be two distinct genetic bases for hyper- $\beta$-lipoproteinaemia, and I suspect that these types differ substantially in their response to treatment. Steinberg (1972) has drawn an important analogy between secondary and primary hyperlipoproteinaemias. In nephrosis, for example, a variety of lipoprotein patterns may be found, depending on the interaction between the underlying lesion and unrelated genetic, dietary, and pathological situations. Steinberg has underlined the probability that a given primary lesion of lipoprotein metabolism may similarly interact with other factors, yielding at least some variability in the plasma lipoprotein pattern. If so, more than one lipoprotein pattern may result from a single aetiology.

Having mentioned some of the difficulties and limitations of this approach to classification, I must state my belief that it works well in practice. According to Tabaqchali, Chait, February, and Lewis (to be published), with even the simplest laboratory information the great majority of hyperlipidaemic patients can be effectively treated.

The first diagnostic procedure is a diligent search for underlying disease, as secondary hyperlipidaemia may account for about one-third of serum-lipid elevations in a general hospital. This is largely a clinical problem, but laboratory procedures are helpful in the detection of hypothyroidism, alcoholism, gout, and renal failure. The early detection of thyroid failure has become easier with the availablity of serum thyroid-stimulating hormone assay; and recognition of overindulgence in alcohol (which is commonly concealed or minimized) can be aided by assay of serum glutamyl transferase (EC 2.3.2.1.) and other indices of hepatic function.

The second general point concerns the detection of affected relatives. Investigation of accessible first-degree relatives is mandatory, unless the index patient clearly has a secondary hyperlipidaemia. By so doing, familial aetiology can be confirmed and early detection of hyperlipidaemia in the relatives may be achieved before overt vascular complications develop.

Thirdly, precautions are required in collecting blood samples. A 12-hour fast is usually insisted $\stackrel{\vec{\sigma}}{\overrightarrow{0}}$ upon, and stasis must be avoided during the vene- $\vec{F}$ puncture (Koerselman, Lewis, and Pilkington, 1961). $\stackrel{\oplus}{\stackrel{\oplus}{9}}$ Taking the sample should be deferred for three? months after myocardial infarction or other major 흠 illness, and for two weeks after minor illness. It is $\frac{\bar{D}}{\bar{\phi}}$ necessary that the subject should consume his $\stackrel{\mathbb{Q}}{\Omega}$ habitual diet for at least two weeks before providing $\approx$ samples for lipid analysis.

The common syndromes seen clinically may now be reviewed. The most frequent, occurring in possibly $\vec{\omega}$ $20 \%$ of men in a London population we are studying, is hyper-pre- $\beta$-lipoproteinaemia, which is by far the commonest form of endogenous hypertriglycerid- is aemia. It occurred in about $13 \%$ of the Californian o community studied by Wood, Stern, Silvers, Reaven, $\overrightarrow{-}$ and von der Groeben (1972). The triglyceride level is o raised, and the cholesterol level is normal or slightly high. The serum is opalescent except in minimally affected patients, the opalescence remaining evenly ${ }_{\mathcal{Q}}$ distributed in the tube after storage at $4^{\circ} \mathrm{C}$ for 18 to 24 hours. On electrophoresis the prominent pre $\beta$ 急 band is evident, whereas the $\beta$ band is normal or even low (see fig). This is the type IV of the $\vec{\theta}$ Fredrickson and WHO classifications. Associated ab-. normalities are obesity in the majority, glucose intolerance and hyperuricaemia in some. The disorder almost certainly predisposes to coronary heart disease (Carlson and Bottiger, 1972) and is common in peripheral vascular disease (Greenhalgh, Lewis, $\underset{\mathbb{Q}}{\stackrel{2}{2}}$ Rosengarten, Calnan, Mervart, and Martin, 1971). $\underset{\vec{F}}{\overrightarrow{7}}$ When severe, it may be accompanied by eruptive $\frac{0}{3}$ xanthomata and lipaemia retinalis, and acute ab- $\frac{3}{\sqrt{2}}$ dominal pain may occur. A syndrome of arthralgia and severe joint tenderness has been described by Goldman, Glueck, Abrams, Steiner, and Herman? (1972). This should not be confused with the muscular pain and weakness which can complicate clofibrate treatment of hyperlipidaemia, in which very highơ levels of creatine kinase (EC 2.7.3.2.) are seen (Langer and Levy, 1968). There is strong evidence $\frac{\text { S }}{5}$ that defective removal of triglyceride from plasma is $>$ the underlying lesion in many patients (Boberg, 으. Carlson, Freyschuss, Lassers, and Wahlqvist, 1972; N Havel, Kane, Balasse, Segel, and Basso, 1970). It must ${ }^{-}$ be emphasized that primary hyper-pre- $\beta$-lipoprotein- $N$ aemia is not synonymous with carbohydrateinduced lipaemia. Carbohydrate-induced hypertriglyceridaemia is a normal response (Mancini et al,o 1973; Glueck, Levy, and Fredrickson, 1969) and occurs to an excessive degree in only about one-half $\stackrel{?}{+}$ of patients with hyper-pre- $\beta$-lipoproteinaemia.

Nicoll, Chait, and I have been studying the uptake of triglyceride by biopsy samples of human adipose tissue from very-low-density lipoprotein labelled in $\vec{\Omega}$ vitro. The patient's own lipoprotein is exchange- 
labelled with triolein tritiated in the fatty acid moiety, and isolated by ultracentrifugation. Nonspecific uptake by adipose tissue is minimal in this preparation and is corrected for by suitable blanks. The time course and temperature coefficients of triglyceride uptake are those of an energy-dependent biological process, and uptake is largely inhibited by cyanide, fluoride, and heating to $100^{\circ} \mathrm{C}$. The magnitude of the uptake in normal subjects in the postprandial state is $0.18 \pm 0.05 \mathrm{mg}$ VLDL triglyceride $/ \mathrm{g}$ wet weight/hour, which is of the same order as published values for turnover of endogenous triglyceride in vivo (Boberg, Carlson, and Freyschuss, $1969)$. In some subjects with primary hyper-pre- $\beta$ lipoproteinaemia there was a subnormal uptake but in one the uptake was rapid; these preliminary findings, which are generally in conformity with in vivo data (Boberg et al, 1972; Havel et al, 1970), may imply some heterogeneity of the mechanism of hypertriglyceridaemia in patients with this form of hyperlipoproteinaemia.

I must mention in passing a situation in which a

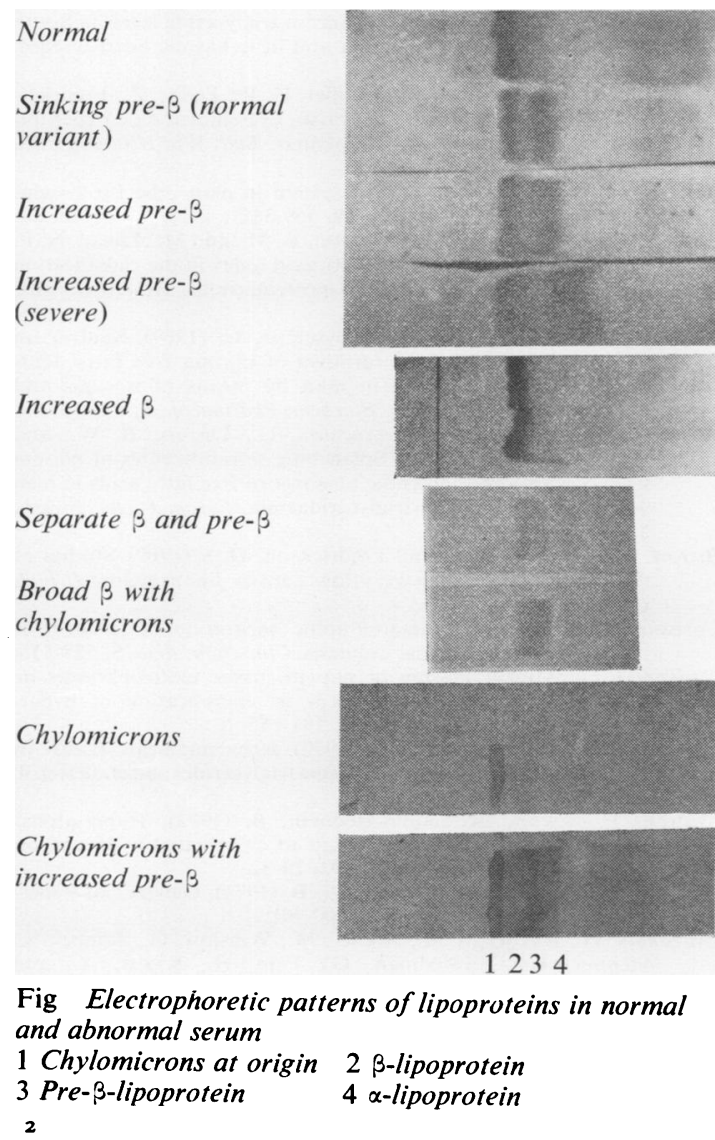

prominent band with pre- $\beta$ mobility is seen in samples with normal triglyceride content (see fig). This 'sinking pre- $\beta$ ' is a common and physiological variant; the pre- $\beta$ material is a polymorphic form of $\beta$-lipoprotein (Berg, 1963; Rider, Levy, and Fredrickson, 1970).

Next most frequent, constituting $6 \%$ of our London population, is hyper- $\beta$-lipoproteinaemia, of which a high cholesterol level is the hallmark; triglyceride concentration is normal or minimally elevated, reflecting the composition of $\beta$-lipoprotein. Serum is clear on inspection, and a heavy $\beta$ band is evident on lipoprotein electrophoresis (see fig). This pattern conforms with type IIa in the WHO classification. There may be no physical signs, but xanthelasmata, and corneal arcus in the young, are suggestive features; tendon xanthoma is a more specific sign. It may be inherited as a single-gene effect, detectable by the age of 1 year in the heterozygous as well as in the much rarer homozygous form. However Carter et al (1971) believe that a much commoner aetiology is a polygenic inheritance, only about $10 \%$ of relatives being affected. The homozygous form leads to coronary disease in childhood, and may be accompanied by aortic stenosis and joint involvement. Lewis and Myant (1967) were unable to demonstrate any abnormality of turnover of cholesterol or bile acid. Decreased fractional removal of the $\beta$-apoprotein has been reported (Langer, Strober, and Levy, 1972).

A third lipoprotein pattern is the combination of the former abnormalities in which $\beta$ - and pre- $\beta$ lipoprotein levels are raised, as are cholesterol and triglyceride concentrations (type IIb of the WHO classification). We have found pure hyper- $\beta$ lipoproteinaemia to be the commonest abnormality in first degree relatives of 18 index patients with this pattern, and believe that this is often the inherited component (Simons, Wahab, Chait, Krikler, and Lewis, 1972). In many of those members of the families who also have raised pre- $\beta$-lipoprotein levels, a coexisting abnormality such as diabetes, obesity, or alcoholism is present. A major reason for distinguishing this type is that it often requires combined therapy directed both at the hypertriglyceridaemia and the hypercholesterolaemia.

Another cause of substantial elevation of both cholesterol and triglyceride levels is the 'broad $\beta$-lipoprotein' abnormality (type III in the Fredrickson classification). This has been regarded as being due to an abnormal molecule, a $\beta$-lipoprotein containing excess triglyceride and possessing atypical electrophoretic (see fig) and ultracentrifugal properties. Recently Levy et al (1971) have obtained tentative evidence that the disorder may be due to accumulation of a normal intermediate in the conversion of 
pre- $\beta$ - to $\beta$-lipoprotein. The disorder is one-tenth to one-twentieth as common a cause of mixed hyperlipidaemia as elevation of $\beta$ - and pre- $\beta$-lipoproteins, but like the latter, is probably strongly atherogenic (Fredrickson et al, 1967). It is readily treated along the same lines as the endogenous hypertriglyceridaemic group (Fredrickson et al, 1967). It is the likely abnormality in patients with palmar xanthomata, but definitive diagnosis requires the demonstration of a lipoprotein of $\beta$ mobility which floats after ultracentrifugation in a medium of density 1.006 (Fredrickson et al, 1967). The aetiology is uncertain. Affected relatives may have the same abnormality or may have elevated pre- $\beta$-lipoprotein levels (Matthews, 1968), and some relationship to the latter disorder is therefore possible.

Next are two uncommon disorders associated predominantly with severe hypertriglyceridaemia. One is chylomicronaemia, presenting often in infancy with abdominal pain and xanthomata (Fredrickson's type I). In adult practice it is vanishingly rare but is diagnosable by the presence of opalescence in fasting serum which floats entirely to the meniscus after storage for 24 hours. The electrophoretic pattern is characteristic with a heavy chylomicron band at the origin (see fig), but some elevation of pre$\beta$-lipoprotein may be shown by analytical ultracentrifugation (Fredrickson, Levy, and Lindgren, 1968). In this disorder deficiency of lipoprotein lipase may be the underlying defect (Havel and Gordon, 1960), but some evidence suggests that the mechanism may not be so simple (Faergeman and Dangaard-Pedersen, 1973). There are no grounds for suspecting that this disorder is atherogenic.

Lastly one may mention those sera containing both chylomicrons and pre- $\beta$-lipoprotein in great excess, the type $\mathrm{V}$ of the Fredrickson and WHO classifications, often regarded as indicating both endogenous and dietary hypertriglyceridaemia (see fig). I have certain reservations about this entity. In the first place the pattern can vary in a given patient, some samples merely showing marked hyper-pre- $\beta$-lipoproteinaemia. Secondly, affected families may show the type $\mathrm{V}$ pattern, or hyper-pre$\beta$-lipoproteinaemia alone (type IV) (Nixon, Martin, Kalab, and Monahan, 1969; Fredrickson, 1969). Finally, I would remind you of the evidence, cited earlier, that the physical properties which define chylomicrons on electrophoresis and ultracentrifugation do not provide definite proof of the origin of the contained triglyceride. My colleagues and I have some evidence that the physical properties, eg, density, of triglyceride-bearing lipoproteins are affected by the quantity of lipid requiring transport as well as by the origin of the lipid (Lewis et al, 1973). I suspect that some of these patients may have

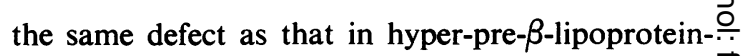
aemia, but in severer degree.

These are not the only abnormalities. Carlson and Kolmodin-Hedman (1972) have pointed out that mildly elevated cholesterol levels may occur as a $\bar{c}$. result of hyper- $a$-lipoproteinaemia, a possibly benign $\vec{\sigma}$ condition, and he has evidence that this can arise in 0 subjects exposed to chlorinated hydrocarbon insecti-ळ cides. Perhaps the strongest argument for meticulous $\overrightarrow{0}$ and detailed investigation of hyperlipidaemias is that further disorders are likely to come to attention. $\vec{\omega}$ Certainly, the laboratory and clinical investigation of the group of disorders is one of the exciting? growing points in clinical science today.

\section{References}

Alaupovic, P (1971). Apolipoproteins and lipoproteins. Atherosclerosi $13,141-146$

Alaupovic, P., Lee, D. M., and McConathy, W. J. (1972). Studies on the composition and structure of plasma lipoproteins. Distribu- $C$ tion of lipoprotein families in major density classes of normal human plasma lipoproteins. Biochim. biophys. Acta, 260, 689-707.

Albers, J. J., and Scanu, A. M. (1971). Isoelectric fractionation and characterization of polypeptides from human serum very low $\overrightarrow{C O}$ density lipoproteins. Biochim. biophys. Acta, 236, 29-37.

Antonis, A., and Bersohn, I. (1960). Serum-triglyceride levels in Southw African Europeans and Bantu and in ischaemic heart-disease. Lancet, 1, 998-1002.

Beaumont, J. L. Carlson, L. A., Cooper, G. R., Fejfar, Z., Fredrickson, D. S., and Strasser, T. (1970). Classification of hyperlipidaemias and hyperlipoproteinaemias. Bull. Wld Hlth Org., 43, 891-915.

Berg, K. (1963). A new serum type system in man-the Lp system. 음 Acta path. microbiol. scand., 59, 369-382.

Billimoria, J. D., Fahmy, M. F., Jepson, E. M., and MacLagan, N. F. (1971). Use of the esterified fatty acid index in the classification and quantitation of hyperlipoproteinaemias. Atherosclerosis, 14, 359-374.

Boberg, J., Carlson, L. A., and Freyschuss, U. (1969). Studies on the total and splanchnic turnover of plasma free fatty acids:and plasma triglycerides in man by means of isotopic and chemical methods. Progr. Eicchem. Pharmacol., 5, 149-159.

Boberg, J., Carlson, L. A. Freyschuss, U., Lassers, B. W., andWahlqvist, M. L. (1972). Splanchnic secretion rates of plasma triglycerides and splanchnic turnover of free fatty acids in men-. with normo- and hypertriglyceridaemia. Europ. J. clin. Invest.,Оి 2, 454-466.

Brown, W. V., Levy, R. I., and Fredrickson, D. S. (1969). Studies of the proteins in human very low density lipoproteins. J. biol.음 Chem., 244, 5687-5694.

Carlson, L. A. (1960). Chromatographic separation of serum lipo $=\frac{D}{2}$ proteins on glass powder columns. Clin. chim. Acta, 5, 528-538.

Carlson, L. A. (1970). Plasma or patient, paper electrophoresis or physician? The four-P problem in classification of hyper-O lipidaemia. Atherosclerosis, 12, 181-183.

Carlson, L. A., and Böttiger, L. E. (1972). Ischaemic heart-disease in relation to fasting values of plasma triglycerides and cholesterol. $\mathrm{N}$ Lancet, 1, 865-868.

Carlson, L. A., and Kolmodin-Hedman, B. (1972). Hyper-alpha-O lipoproteinemia in men exposed to chlorinated hydrocarbon pesticides. Acta med. scand., 192, 29-32.

Carter, C. O., Slack, J., and Myant, N. B. (1971). Genetics of hyper lipoproteinaemias. Lancet, 1, 400-401

Christakis, G., Rinzler, S. H., Archer, M., Winslow, G., Jampel, S.; Stephenson, J., Friedman, G., Fein, H., Kraus, A., and James, G. (1966). The anti-coronary club: a dietary approachO to the prevention of coronary heart disease-a 7-year report $\overrightarrow{\mathbb{D}}$ Amer. J publ. Hlth, 56, 299-314.

Cramp, D. G., and Robertson, G. (1968). The fluorometric assay ofD triglyceride by a semi-automated method. Analyt. Biochem. 25, 246-251. 
Dayton, S., Pearce, M. L., Goldman, H., Harnish, A., Plotkin, D., Shickman, M., Winfield, M., Zager, A., and Dixon, W. (1968). Controlled trial of a diet high in unsaturated fat for prevention of atherosclerotic complications. Lancet, 2, 1060-1062.

Faergeman, O., and Dangaard-Pedersen, F. (1973). Increase in post heparin lipase activity by oxandrolone in familial hyperchylomicronemia. Scand. J. Lab. clin. Invest., in press.

February, A., Mattock, M., Chait, A., and Lewis, B. (1972) Chylomicra and very-low density lipoproteins-are they functionally distinct? Clin. Sci., 43, 4P.

Fredrickson, D. S. (1969). Plasma lipoproteins: micellar models and mutants. Trans Ass. Amer. Phycns, 82, 68-86.

Fredrickson, D. S., Levy, R. I., and Lees, R. S. (1967). Fat transport in lipoproteins-an integrated approach to mechanisms and disorders. New Engl. J. Med., 276, 34-44, 94-103, 148-156, 215-225, and 273-281.

Fredrickson, D. S., Levy, R. I., and Lindgren, F. T. (1968). A comparison of heritable abnormal lipoprotein patterns as defined by two different techniques. J. Clin. Invest., 47, 2446-2457.

de Gennes, J. L. (1971). Les hyperlipidémies idiopathiques. Proposition d'une classification simplifiée. Presse méd., 79, 791-795.

Glueck, C. J., Levy, R. I., and Fredrickson, D. S. (1969). Immunoreactive insulin, glucose tolerance and carbohydrate inducibility in types II, III, IV, and V, hyperlipoproteinemia. Diabetes, 18, 739-747.

Goldman, J. A., Glueck, C. J., Abrams, N. R., Steiner, P., and Herman, J. H. (1972). Musculoskeletal disorders associated with type-IV hyperlipoproteinaemia. Lancet, 2, 449-452.

Greenhalgh, R., Lewis, B., Rosengarten, D. S., Calnan, J. S., Mervart, I., and Martin, P. (1971). Serum lipids and lipoproteins in peripheral vascular disease. Lancet, 2, 947-950.

Havel, R. J., and Gordon, R. S., Jr. (1960). Idiopathic hyperlipemia: metabolic studies in an affected family. $J$, clin. Invest. 39,1777 1790.

Havel, R. J., Kane, J. P., Balasse, E. O., Segel, N., and Basso, L. V. (1970). Splanchnic metabolism of free fatty acids and production of triglycerides of very low density lipoproteins in normotriglyceridemic and hypertriglyceridemic humans. J. clin. Invest., 49, 2017-2035.

Keys, A. (1966). Epidemiological studies related to coronary heart disease: characteristics of men aged 40-59 in seven countries. Acta med. scand., Suppl., 460.

Koerselman, H. B., Lewis, B., and Pilkington, T. R. E. (1961). The effect of venous occlusion on the level of serum cholesterol. J. Atheroscler. Res., 1, 85-91.

Langer, T., and Levy, R. I. (1968). Acute muscular syndrome associated with administration of clofibrate. New. Engl. J. Med., 279, 856-858.

Langer, T., Strober, W., and Levy, R. I. (1972). The metabolism of low density lipoprotein in familial Type II hyperlipoproteinemia. J. clin. Invest., 51, 1528-1536.

Lees, R. S., and Hatch, F. T. (1963). Sharper separation of lipoprotein species by paper electrophoresis in albumin-containing buffer. J. Lab. clin. Med., 61, 518-528.
Lewis, B., Chait, A., February, A. W., and Mattock, M. (1973). Functional overlap between 'chylomicra' and 'very low density lipoproteins' of human plasma during alimentary lipaemia. Atherosclerosis, in the press.

Lewis, B., and Myant, N. B. (1967). Studies in the metabolism of cholesterol in subjects with normal plasma cholesterol levels and in patients with essential hypercholesterolaemia. Clin. Sci., 32, 201-213.

Levy, R. I., Bilheimer, D. W., and Eisenberg, S. (1971). The structure and metabolism of chylomicrons and vey low density lipoproteins. In Plasma Lipoproteins: Biochemical Society Symposium, No. 33, edited by R. M. S. Smellie, pp. 3-17. Academic Press, London and New York.

Mancini, M., Mattock, M., Rabaya, E., Chait, A., and Lewis, B. (1973). Studies of the mechanisms of carbohydrate-induced lipaemia in normal man. Atherosclerosis, in press.

Matthews, R. J. (1968). Type III and IV familial hyperlipoproteinemia. Amer. J. Med., 44, 188-199.

Miettinen, M., Turpeinen, O., Karvonen, M. J., Elosuo, R., and Paavilainen, E. (1972). Effect of cholesterol-lowering diet on mortality from coronary heart disease and other causes. A twelve-year clinical trial in men and women. Lancet, 2, 835-838.

Nichols, A. V., and Smith, L. (1965). Effect of very low-density lipoproteins on lipid transfer in incubated serum. J. Lipid Res., 6, 206-210.

Nixon, J. C., Martin, W. G., Kalab, M., and Monahan, G. J. (1969). Type V hyperlipoproteinemia : a study of a patient and family. Clin. Biochem., 2, 389-398.

Rider, A. K., Levy, R. I., and Fredrickson, D. S. (1970). 'Sinking' prebeta lipoprotein and the Lp antigen. (Abstr.) Circulation, 42, Suppl. 3, 10.

Shaper, A. G., and Jones, K. W. (1959). Serum-cholesterol, diet and coronary heart-disease in Africans and Asians in Uganda. Lancet, 2, 534-537.

Simons, L., Wahab, S., Chait, A., Krikler, D. M., and Lewis, B. (1972). A study of hyper- $\beta$ - and hyperpre- $\beta$-lipoproteinaemia. (Abstr.) Brit. Heart J., 34, 960.

Spritz, N., and Mishkel, M. A. (1969). Effects of dietary fats on plasma lipids and lipoproteins: an hypothesis for the lipid-lowering effect of unsaturated fatty acids. $J$. clin. Invest., 48, 78-86.

Steinberg, D. (1972). Some observations on hyperlipoproteinemias and their classification. Circulation, 45, 247-251.

Stone, M. C., Thorp, J. M., Mills, G. L., and Dick, T. B. S. (1970). Comparison of membrane filtration and nephelometry with analytical ultracentrifugation, for the quantitative analysis of low density lipoprotein fractions. Clin. chim. Acta, 30, 809-828.

Werner, M., and Jones, A. L. (1972). Characterization of electrophoretic lipoprotein fractions: immunochemical and electron microscopic studies. Clin. Chem., 18, 534-538.

Wood, P. D. S., Stern, M. P., Silvers, A., Reaven, G. M., and von der Groeben, J. (1972). Prevalence of plasma lipoprotein abnormalities in a free-living population of the Central Valley, California. Circulation, 45, 114-126. 